This is the peer reviewed version of the following article:

This is the peer reviewed version of the following article: Macduff, C. and Goodfellow, L. and Nolfi, D. and Copeland, S. and Leslie, G. and Blackwood, D. 2016. Slipping through the net: the paradox of nursing's electronic theses and dissertations. International Nursing Review. 63 (2): pp. 267-276.,

which has been published in final form at http://doi.org/10.1111/inr.12256.

This article may be used for non-commercial purposes in accordance with Wiley Terms and Conditions for Self-Archiving at http://olabout.wiley.com/WileyCDA/Section/id-828039.html 


\title{
Slipping through the net: \\ the paradox of nursing's electronic theses and dissertations
}

\begin{abstract}
Aim: The study's main aim was to gain in-depth understanding of how nurse scholars engage with electronic theses and dissertations. Through elicitation of opinions about challenges and opportunities, and perceptions of future development, the study also aimed to influence the design of a new international web-based forum for learning and sharing information on this topic.

Background: Electronic theses and dissertations provide an opportunity to radically change the way in which graduate student research is presented, disseminated and used internationally. However, as revealed by a multi-national survey in 2011, many nurse scholars in vanguard universities have little awareness of how to find and exploit this ever-expanding global knowledge resource that is increasingly available free in full text format. Within this context more detailed understandings of nurse scholars' thinking and actions are required.
\end{abstract}

Methods: A qualitative approach using a semi-structured interview guide was utilised to elicit perceptions from 14 nurse scholars.

Results: Thematic analysis of the interviewees' responses identified six major themes: initial exposure and effect; searching; accessing; handling; using; and evaluation. Insights were gained about the value of these resources and behaviours in using them as exemplars for structure, format and methodology.

Conclusion and Implications for Nursing and Nursing Policy: Despite the small study size, the findings added valuable new insights to the overview gained from the 2011 survey. These have been used to inform development of a new global initiative: the International Network for Electronic Theses and Dissertations in Nursing (INETDIN). Featuring an educational website (www.inetdin.net), this initiative aims to support and challenge nursing's policy makers, practitioners and especially educators to utilise this neglected but exponentially increasing wellspring of international nursing knowledge.

\section{Key words}

Electronic Theses and Dissertations; ETDs; nursing research; dissemination; United States; United Kingdom; international network; INETDIN 


\section{I ntroduction}

For over a decade an increasing number of universities around the world have encouraged graduates to submit their theses and dissertations in electronic format. Indeed, many universities now make this a requirement and make these electronic theses and dissertations (ETDs) available through in-house digital libraries known as Institutional Repositories (IRs). Among many reasons for this is the realization that graduate student research is more easily accessible to a wider audience if it is available electronically. Early adopters of electronic submissions found that ETDs are consulted more frequently than traditional paper theses or dissertations (Moxley 2001). Figures from Virginia Tech demonstrate the scale of increase in use and how quickly scholars turn to online methods of access (Virginia Tech 2011).

Concurrently there have also been initiatives to create large-scale catalogues, databases and portals which provide access to ETDs at no cost to the user. The Networked Digital Library of Theses and Dissertations (NDLTD) [http://www.ndltd.org] plays a key role in providing and promoting access to discovery platforms and search interfaces for finding ETDs such as through its Global ETD Search [http://www.ndltd.org/resources/find-etds]. Other regional and national collaborations include DART-Europe [http://www.dart-europe.eu], Cybertesis [http://www.cybertesis.net/], the British Library's 'Electronic Theses Online Service' (EThOS) [http://ethos.bl.uk] and the National Library of Australia's 'Trove' repository [http://trove.nla.gov.au].

Copeland (2010) identifies some of the early concerns about the creation of ETDs but also the benefits and growth in their availability and use internationally. The number of ETDs, and ease of access to them, now provides substantive opportunities for nurses and nursing to benefit. Macduff (2009) asserts that ETDs have the potential to radically change the nature and scope of the dissemination and use of doctoral research: not only through improved access to the results but also by offering researchers the opportunity to use a variety of multimedia techniques to express their research results in different ways. These potential benefits are as applicable to nursing as they are to other disciplines. 


\section{Background}

Within this ambit of opportunity, it is important to ask what nursing is, and has been, doing to exploit such possibilities. Literature searching would suggest that the answer is: very little indeed for the past ten years. Our work during the earlier part of this period (e.g. Goodfellow 2004, 2009; Macduff 2009) identified a dearth of academic writing on the topic and a similar dearth of research. More recent searching of research databases, including CINAHL and Medline (in 2014), showed an almost entirely unchanged picture.

This situation seems remarkable when one considers the expansion in doctoral (and masters) level nursing education globally (Ketefian et al. 2005), and the related proliferation of thesis and dissertation outputs. Focusing on the UK and Ireland, McKenna et al. (2001) estimated an average of 35 students starting doctoral nursing programmes at the start of the millenium. In academic year 2013/2014, 135 students graduated with doctorates in nursing within the UK alone (HESA 2015). Moreover a search of the British Library's EThOS database of theses combining the search term 'nursing' and the year of issue (i.e. date of award) yields 61 theses for 2004 and 154 for 2014. The American Association of Colleges of Nursing annual report for 2013 shows similar expansion, with 620 nursing scholars graduating that year with research-focused doctorates and 1,858 with practice focused doctorates (AACN 2013). Accordingly the annual number of new doctoral nursing graduates globally is likely to be in the thousands, many of whom submit their work electronically.

As such, a paradoxical situation seems to prevail whereby this form of knowledge production is increasing exponentially but we know very little about its uptake and use. This raises concerns that there may be lost opportunities to improve health practice, education and policy if this proliferating knowledge is not being harnessed and debated. Thus in 2011, in order to assess the scale of this knowledge gap in selected geographical areas, a research team comprising a nurse scholar and an academic librarian from Duquesne University in the U.S., Robert Gordon University in the U.K. and Curtin University in Australia undertook the first international study of nurses' engagement with ETDs (Goodfellow et al. 2012). An online survey was used to ascertain information about the level of knowledge and use of ETDs, and associated databases, by 
faculty, graduate students and alumni of schools of nursing in Australia, New Zealand, the United Kingdom (U.K.) and the United States (U.S.). Importantly, the survey focused on schools that were known to be in the vanguard of ETD developments as manifest in their having Institutional Repositories and having their ETDs listed in key national and international catalogues. The survey revealed that respondents $(\mathrm{N}=209)$ had little knowledge about ETDs or the sources that provide access to them. Specifically, only $44 \%$ knew how to access ETDs through their institutions' ETD digital libraries and only $18 \%$ knew how to access ETDs in a national or international ETD collection. In addition, only $27 \%$ had cited an ETD in a publication. The results showed that even in these vanguard universities from four different countries, nursing scholars were not using ETDs to their fullest potential.

While this initial study provided overview and highlighted a pervasive need for more education and awareness raising, the survey method limited depth of insight into the nature of engagement with ETDs and related individual reasoning. In anticipation of this the survey participants were asked to provide contact details if they might be willing to participate in further ETD studies. Forty four of the 209 participants did so. This afforded opportunity to seek more detailed insights into nurse scholars' experiences and thinking so as to better understand what is/is not happening in terms of engagement with ETDs. Such understanding would be useful at a practical level to inform the development of action to raise awareness and advocate for improvements in policy, practice and education around this global resource. This paper reports on the key findings of this qualitative study conducted during 2013 and subsequent developments.

\begin{abstract}
Aim
The study's primary aim was to gain in-depth understanding of how nurse scholars engage with electronic theses and dissertations. Through elicitation of opinions about challenges and opportunities, and perceptions of future development, the study also aimed to influence the design of a new international web-based forum for sharing information on this topic and advocating improvements.
\end{abstract}




\section{Methods}

\section{Design}

The study design was qualitative in nature. It took the form of telephone interviews with the intention of eliciting individuals' detailed descriptions of how they engage with ETDs, especially in terms of perceived challenges and benefits. This involved generating contextualised description (Ritchie 2003) with subsequent exploration by the researchers based on a broadly interpretivist approach (Snape et al. 2003). This draws on ideas from Ritchie et al. (2003) whose "Framework" approach also informed our approach to data analysis.

\section{Sample and Recruitment Activities}

A list of potential participants including current PhD students, faculty and alumni of Schools of Nursing was created from those who had participated in the Goodfellow et al. (2012) study and had expressed interest in participating in other studies related to ETD development. Once the list was created, the research team was given the email addresses of potential participants to contact corresponding to geographical location. An email invitation describing the study was sent together with a consent form. Those who responded positively and returned an appropriately signed consent form were contacted by a member of the research team and a date was scheduled for interview.

\section{Instrument}

The interview schedule (Table 1) was semi-structured to explore participants' past and current engagement with ETDs, asking for in-depth descriptions and explanations of perceived benefits and challenges. It was also used to ask how any future developments could best be advanced. As such, the schedule served to guide the researchers to maintain a systematic yet flexible approach to the interviews. Prompts were also used to help participants expand on, or further clarify, specific responses. This approach was considered the most appropriate method of obtaining in depth understanding of the participants' perspectives (Munhall 2012).

To ensure that the questions would elicit the desired information (Van Teijlingen et al. 2002), the schedule was piloted with one faculty member who 
had participated in the original survey (Goodfellow et al. 2012). The interview, lasting 32 minutes, was digitally recorded and transcribed verbatim. The transcribed text was reviewed by the international research team and only minimal refinements to the interview schedule were required to improve elicitation of background and demographic information. This testing and clarification was important as two members of the research team in each country were to be involved in carrying out interviews with their respective national participants.

\section{Data Collection Procedures}

Informed consent was obtained prior to data collection. Interviews were conducted by telephone or Skype, as agreed by each researcher and participant. This approach is particularly useful when there is widespread geographical dispersal of participants (Musselwhite et al. 2007; Smith 2005).

\section{Ethical Considerations}

Approvals to conduct this study were obtained from the Institutional Review Board at Duquesne University (Protocol \# 2013/12/12) and the relevant ethics committees at Robert Gordon University (Protocol 13/01) and Curtin University (Protocol 25/2010). Electronic consent forms were stored on the researchers' password protected computers. Interview data collected via digital recorders were deleted after the interviews were transcribed and reviewed by the research team. Participants' identities were kept confidential and each participant transcript was given a reference number.

\section{Data Analysis}

Piloting of analysis processes is inherently useful to ensure rigorous analysis (Van Teijlingen et al. 2002). Transcribed data obtained from the pilot interview served as a basis for ensuring quality of the study's analysis procedures. A thematic approach was developed to analyse the text from the interview, drawing primarily on processes from the "Framework Analysis" method (Ritchie et al. 2003) and included familiarisation with data, identifying a thematic framework and charting/mapping. The use of a matrix layout enabled initial coding comments to be recorded alongside key related textual excerpts through which emergent clusters of meaning were constituted as themes. This 
process was developed and applied by the lead author, then its principles and outputs were shared and interrogated by other team members. After minor modifications it was agreed to be a systematic, reproducible approach. This process was subsequently used to analyse all transcripts.

Transcriptions were undertaken by a professional online transcription company. Each transcription was reviewed along with the audio recording by the research team member who had conducted the interview. Prior to analysis, deidentified data from each interview were entered into a matrix.

Analysis of data followed the process used for the pilot interview. In addition, cross case analyses used a matrix layout to demonstrate the main themes from the interviews across countries. This approach to summarising and synthesising data draws on the work of Miles et al. (2014) and helps to summarise convergences and divergences of perspectives on particular issues. In doing so it enabled review for data saturation. A narrative summary of the characteristics of participants, and commonalities and differences within the findings, was constructed for each country. The final part of the analyses involved integration of findings from each of the participating countries. This involved identifying major themes, common sub themes and illustrative examples.

The processes described above include strategies of testing, checking and making interpretation explicit within and across cases that enhanced the study's trustworthiness. A clear audit trail exists of data collection, analysis and synthesis. Moreover, the use of participants own words in quotations in the findings section of this paper contributes to the credibility of findings, allowing the reader to obtain a sense of the voice of these stakeholders and to make their own inferences about potential transferability of findings to other contemporary contexts. 


\section{Results}

\section{Participants}

Invitations to participate were sent to 44 email addresses in total: 22 from the U.K.; 16 from the U.S. and 6 from Australia/New Zealand. One additional email invitation was sent to those who did not respond.

A total of 14 nurse scholars including current PhD students, faculty and alumni from Schools of Nursing participated in the study. Seven participants were recruited from the U.S., with the same number including the pilot interviewee from the U.K. Summary details of the fourteen participants are provided in Table 2. All interviews were conducted by telephone with the exception of one interview conducted via Skype. All interviews were audio recorded. Interviews varied widely in terms of duration, from 11 to 64 minutes, reflecting different participant levels of engagement with, and interest in, ETDs.

\section{Overview of Themes}

Analyses of the interviews showed broad convergence in the views of the participants including current PhD students, faculty and alumni, and there were very few areas of difference between the two countries. This pattern of convergence was evident from a relatively early stage in data collection and analysis, and substantive data saturation was achieved within the 14 interviews. Overview of the resultant themes and sub-themes across participants is presented in Table 3, including summative explanatory examples and comments from the researchers. The six main themes primarily reflect the common processes that emerged as important. The 27 sub-themes provide more detailed insights into aspects of engagement. In summarising the findings below, each theme is exemplified with verbatim quotations cited to reflect the content of selected sub-themes. Findings which shed new light on processes and related thinking are deliberately given more space than those which solely confirm the previous survey findings. 


\section{Theme 1. I nitial exposure and effect of ETDs}

In both the U.S. and the U.K., students usually gained initial awareness of ETDs through knowledge provision/instruction:

I first became aware of them around the time I started doing my own PhD work.......somebody from the library came and gave us a talk on how thesis would be sent to the university library using the electronic thesis format (UK 1; faculty)

This was perceived by the students as being useful in terms of gaining an understanding of output:

...I was wondering what the thesis should look like when it's finished, so I read through some of the data, and then I had a little bit of an idea what the end product must look like... (US 3; faculty)

The convenience and benefits of easy access to ETDs appealed strongly to students:

Obviously having access to an electronic dissertation instead of going to the library and accessing it or borrowing it or to the department was something very tempting and useful. (UK 4; current professional doctorate student)

There was also appeal for faculty, some of whom had become aware of ETDs through searching for such material in a deliberate but unstructured way:

... I was aware that other people had electronic theses and occasionally I would do a search, just sort of a general search to find stuff. (UK 2; faculty)

\section{Theme 2. Process of engagement: searching for ETDs}

Students and faculty usually searched using their local IR. There was often a lack of knowledge of relevant sources external to their own institution. Wider search strategies tended to lack precision and proceeded intuitively or through serendipity:

I was never able to, other than on the (name of own IR omitted) site. I don't know how to even begin to look for them outside. (US 2; current PhD student)

You can do a Google search, but it doesn't necessarily come up with the databases. I find it points you to particular universities' libraries. But it doesn't necessarily come up with any of the databases that you would find a thesis on, and I think that would be really useful if I knew which database to look at. (UK 1; faculty) 


\section{Theme 3. Process of engagement: accessing ETDs}

The process of accessing ETDs in their entirety could be difficult at times:

There were some universities - I can't remember exactly which ones they would've been - you know, where there wasn't full access... (US 1; current PhD student)

Equally, access experiences could be excellent:

It's definitely fast, very convenient and it saves a lot of time going back and forth. (UK 4; current professional doctorate student)

\section{Theme 4. Process of engagement: handling ETDs}

Once full text ETDs had been accessed, readers had strategies for selecting parts of most relevance:

Normally I will read the table of contents first and try to locate the part which is most interesting to me, and then I will go - normally I will read the whole abstract ...I will read that part, and then I will go directly to the part which I'm most interested in. (US 3; faculty)

However, ETDs offered a particularly valuable option for fast appraisal:

If they're in PDF then obviously you can search within the documents and that's an advantage of it. (UK 6; faculty)

The electronic format could not only enable swifter accessing of theses and searching within them, but also enable larger numbers of them to be handled:

It's been really useful to just dip in, have a flavour of them, have a flavour of the structure as well.... Or maybe just to get some key theorists in that particular area but not have to print out or go and collect or whatever, you know... You can actually scan maybe half a dozen to ten whereas before you would have been physically looking at maybe one or two. (UK 5; current PhD student)

However, on-screen reading could be difficult and students had developed strategies for deciding how to handle ETDs and whether to keep them:

The only obstacle - well, what would make me tired would be staring at the screen for too long and sometimes you need to have hardcopy or you need to highlight things or you need to know where to go back and pick up from where you left or what's important to you and so that's one thing. The other thing storage, of course we have the access to the dissertation and you can get a copy onto a USB or your desktop but then storage is limited if you're using university computers. (UK 4; current professional doctorate student) 
In exploring how readers handled these large documents, one member of faculty highlighted how individual preferences could markedly differ:

Well, I mean, I've had some interesting conversations with students. Because I said examiners, you know, very often don't read them in a linear fashion. And their supervisor will look at them and say: "I do". So some people definitely do. They sort of open it at page one and proceed through to page 350. (UK 2; faculty)

\section{Theme 5. Process of application: using ETDs}

At the heart of our study was exploration of why and how readers used ETDs. Firstly, ETDs could be used instrumentally in early stages of research:

As a PhD. level, you know, PhD. candidate, I think it's an indispensable resource because if you're looking at, you know, you're building your research protocol build based upon the current state of knowledge - I mean it's an intricate part of your review of the literature. (US 1; current PhD student)

As noted above, ETDs could also act as early exemplars of subject content. However one of the strongest themes to emerge was the added value of ETDs as exemplars of methodology:

I looked very carefully at her methodology for that instrument and I decided it was a terrible instrument. Now, if I had just gotten a general article about that manuscript, which I did initially and then found the dissertation, you - it could be very misleading. (US 2; current PhD student)

I just downloaded several theses from ETD. First, I can learn the methodology what they are using. Why are they use that one quite properly because this thesis has been submitted, so I really can compare to my study what I'm going to do. (UK 7; current PhD student)

Moreover ETDs could act more generally as exemplars of structure and format:

Sometimes I might look at it as a whole and see the structure and see how, you know, a submitted dissertation for a PhD, say for instance looks or should be or see even the structure within a chapter or all chapters and the layout of the dissertation, references. . . (UK 4; current professional doctorate student) 


\section{Theme 6. Evaluation: conceptions, academic culture, and change related to ETDs}

The interviews also elicited evaluative and reflective insights on conceptions, academic culture and change related to ETDs. In evaluating impact, faculty often contrasted present experiences with past:

I can remember trying to complete for my masters thesis, and I had to get you know thesis on microfilm. (UK 3; faculty)

... when I went back to work many years after my PhD, and I just thought I would have a look to see how many people had read it in the library. And the answer was nobody. I was the first person to go down and look at it... (UK 2; faculty)

Despite the clear benefits of increased accessibility, almost all interviewees (without prompting) identified a clear need to raise awareness of ETDs and proactively educate potential readers in how to use them optimally:

Initially, something to raise awareness of it and then perhaps some kind of online forum or information giving session that gives you a quick guide to how to access them and suggestions for how to use them. (UK 2; faculty)

One member of faculty ran an interdisciplinary research methods module for postgraduate students which proactively used ETDs:

When you can actually put up and actually hold an online forum discussion and the interesting part about it is when you start people into this they'll actually say well, I actually found one (ETD)...that's better than what you recommended and this is where it is...That's what develops collegiality. It displays an understanding... (UK 3; faculty)

In this context useful insights were given into the comparative benefits of the ETD compared to a journal article:

If you're trying to develop an appreciation among postgraduate students, the only way you can develop that appreciation is by actually saying there's the whole thing. I have to say I'm thinking of two people's work when I speak about this ...they were both extensive projects, but the work itself was broken down for publication..., When it was being disseminated, it was being disseminated in an almost like fractured way...It's not until I go back and I read the whole thing that I get a sense of what this is about. And I suppose that's what ETDs allow us. (UK 3; faculty)

However, other faculty were more ambivalent:

It's actually not that common that it's useful. Because mostly when people have done something that's worth knowing about, they then follow up with a paper 
and went back to the press anyway. But sometimes you get a bit more fuller information from the PhD. (UK 2; faculty)

Indeed there was a strong sense across most of the interviews that ETDs had not yet become embedded as an integral part of academic culture. Even recent ETD authors had little sense of their output's impact:

I don't know how my own dissertation impacted others but I am glad and happy that others could use that and it is available internationally... There will definitely be an impact on nursing as well as to our own statistician but I do not know how to measure that at this point. (US 6; alumni)

\section{Discussion}

Before discussing the results, it is important to acknowledge the limitations of the study. Given that the 14 interviewees were self-selecting and motivated enough to respond, it seems likely that they had more inherent interest in ETDs than other nursing scholars. Nevertheless, their perceptions largely confirm the limited impact ETDs seem to have made on nursing scholarship and, by implication, nursing practice.

Across these 14 interviewees, areas of difference between student participants, alumni and faculty were minimal and related primarily to the nature of their roles. For example, faculty supervising doctoral students understandably were able to draw on experiences of assessment of ETDs. Moreover, there were very few differences in findings across the two different countries. Rather, where there were areas of difference within the interviews, these seemed to reflect individual preferences or opinions such as attitudes to reading text on screen, ways of reading theses and beliefs about the relative usefulness of ETDs compared to journal articles.

The latter issue might reasonably be seen as a fundamental question for ETD advocates whom it would seem are failing to persuade fellow nursing scholars of the comparative benefits (Goodfellow et al. 2012). However, as can been seen in the findings, faculty can make a strong case for these centred on the more substantive evidence of theoretical engagement and methodological application that an ETD may provide.

This case is bolstered by some of the strongest and most novel of the convergent themes in our study: those illuminating why and how students and 
faculty need readily accessible exemplars of thesis structure, format and methodology. Some empirical support for this need is also found in the only indepth study of ETD dissemination to date (Macduff 2009), which found that methodological annexes to the ETD were frequently accessed. The latter author also uses the analogy of building a house for thesis construction (Macduff 2008) and it seems clear from the present study that consideration of examples of overall design (i.e. ETD exemplars for structure and format) are of importance along with consideration of particular bricks or buttresses (i.e. journal papers).

Nevertheless, other strong themes suggest that access to such exemplars is currently limited for scholars due to lack of knowledge about how to seek ETDs beyond the local IR. The study offered new insights into how students learn about ETDs, with information about the local IR seemingly prominent in educational sessions provided by faculty and library staff. A number of interviewees also described using very general Google searches, with mixed results. It was striking how strongly both students and faculty felt about lack of awareness and proactive education about ETDs. Moreover, felt need for "onestop" national and international ETD portals co-existed with relative ignorance of how to find and engage with existing exemplars of these (such as NDLTD). In effect this self-selecting cohort gives further insight into how little understanding of present resources there is and how, once located, these may not meet needs.

In reflecting on the findings of this qualitative study which invited wider considerations from interviewees, it is also important to consider what was not said. Given the usefulness of methodology exemplars, it is interesting that only one person (faculty) mentioned the issue of plagiarism. Finally, although one member of faculty was using ETDs creatively and proactively to educate across disciplines, there was no sense across the interviews of ETDs transforming the nature and scope of the thesis itself. Tales of producing or using theses with video or audio clips, or imaginative formats, were noticeable by their complete absence. 


\section{Conclusion and Implications for Nursing and Nursing Policy}

At first consideration, nursing theses and dissertations may seem peripheral to the pressing global healthcare issues of the day. However if we accept that nurses are the largest healthcare profession worldwide, and that nursing's doctoral outputs represent a key part of its highest level of scholarship, the need for better dissemination, awareness and development comes more sharply into focus. In effect thousands of nursing ETDs, representing many years of scholarship, are produced annually around the world. Yet our own profession seems largely unaware of these. The idea that the best doctoral and masters work will necessarily go on to be published in academic journals simply has no evidence base (Macduff et al. 2015).

Given then that our contemporary literature review and research suggests that very little progress has been made in nursing's engagement with ETDs, there is clear need for better global intelligence in this sphere. Research with countries whose first language is not English is a priority. In addition to conducting survey research across these countries, there is scope for more detailed documentary analyses and case studies. There is a wealth of research contained within theses across the world but, until recently, even the most diligent researcher would find these inaccessible.

There is a clear need for action now. At a policy level this may be started by raising awareness with a range of international organisations such as the International Council of Nurses and the International Academy of Nursing Editors. At local and national levels, nursing's educational institutions need both information and persuasion to start to realise the benefits of the work being produced by their own students and staff, learning also from the work of other vanguard institutions in this sphere. In turn this will start to filter through to practitioners, some of whom will themselves be engaged in research degrees such as Professional Doctorates.

To this end the authors have used the detailed findings from this research, along with the 2011 study, to inform the design and content of a new website [www.inetdin.net] which aims to be a first point of reference for nursing scholars engaging with ETDs. The INETDIN website explains how best to access ETDs, giving links to key IRs, national portals, and international portals. It also clarifies 
benefits and challenges in creating an ETD. In 2015, in its first two months, the website attracted almost 3,500 views from countries around the world.

The website is just part of a new global initiative: the International Network for Electronic Theses and Dissertations in Nursing The main aim of INETDIN is to build an innovative global community of users and developers of ETDs in nursing that will achieve the awareness raising and advocacy work that our research shows is necessary.

It is difficult to avoid the conclusion that the opportunities that the worldwide web should be bringing for nursing's doctoral dissemination are largely slipping through the net. Further policy advocacy, initiatives and research are needed to address this detrimental situation for nursing scholarship globally.

\section{References}

American Association of Colleges of Nursing (2013) Moving the conversation forward; advancing higher education in nursing. Annual Report 2013. Available at: http://www.aacn.nche.edu/aacn-publications/annualreports/AnnualReport13.pdf (accessed 10 March 2015)

Copeland, S. (2010) Electronic Theses and Dissertations: promoting 'hidden' research'. In R. Rikowski (Ed). Digitisation Perspectives. Rotterdam: Sense Publishers. pp. 103 - 113 ISBN 978-94-6091-297-9.

Goodfellow, L.M. (2004) Electronic Theses and Dissertations. In J. Fitzpatrick \& K. Montgomery (Eds). Internet for Nursing Research: A Guide to Strategies, Skills, and Resources. New York: Springer. pp. 26-37.

Goodfellow, L.M. (2009) Electronic theses and dissertations: a review of this valuable resource for nurse scholars worldwide. International Nursing Review. 56 (2): $159-65$.

Goodfellow, L.M. et al. (2012) Nurse scholar's knowledge and use of electronic theses and dissertations. International Nursing Review. 59: 511-518. 
Higher Education Statistics Agency (HESA) (2015) Statistics for students graduating with doctorates in nursing 2013/2014. Available at: https://www.hesa.ac.uk/dox/dataTables/studentsAndQualifiers/download/Qualsu b1314.xIsx Accessed 24/9/15 (accessed 28 September 2015)

Ketefian, S. et al. (2005) Issues and challenges in international doctoral education in nursing. Nursing and Health Sciences. 7, 150-156.

McKenna, H. \& Cutcliffe, J. (2001) Nursing Doctoral Education in the United Kingdom and Ireland. The Online Journal of Issues in Nursing. The American Nurses Association. Available at:

http://www. nursingworld.org/MainMenuCategories/ANAMarketplace/ANAPeriodic als/OJIN/TableofContents/Volume62001/No2May01/ArticlePreviousTopic/UKandI relandDoctoralEducation.aspx (accessed 29 September 2015)

Macduff, C. (2008) Editorial: The PhD thesis as a virtual guest house. Journal of Clinical Nursing. 17: 2381-2383.

Macduff, C. (2009) An evaluation of the process and initial impact of disseminating a nursing e-thesis. J ournal of Advanced Nursing. 65 (5): 10101018.

Macduff, C. et al. (2015) Harnessing our rivers of knowledge: time to improve nursing's engagement with Electronic Theses and Dissertations. Journal of Advanced Nursing. Article first published online: 28 September 2015 doi: $10.1111 /$ jan. 12821

Miles, M., Huberman, M., \& Saldana, J. (2014). Qualitative Data Analysis: a methods sourcebook. ( $3^{\text {rd }}$ edition) Thousand Oaks, California: Sage.

Moxley, J. M. (2001) Universities should require electronic theses and dissertations. Educause Quarterly. 24 (3): 61-63. Available at: http://net.educause.edu/ir/library/pdf/eqm0139.pdf (accessed 2nd August 2014).

Munhall, P. L. (2012) Nursing Research: A Qualitative Perspective ( $5^{\text {th }}$ ed). Sudbury, MA: Jones \& Bartlet. 
Musslewhite, K., Cuff, L. McGregor, L. \& King, K. (2007) The telephone interview is an effective method of data collection in clinical nursing research: a discussion paper International J ournal of Nursing Studies. 44: 1064-1070.

Ritchie, J . (2003) The applications of qualitative methods to social research. In J. Ritchie and J. Lewis (Eds). Qualitative Research Practice: a guide for social science students and researchers. London: Sage.

Ritchie, J., Spencer, L. \& O'Connor, W. (2003) Carrying out qualitative analysis. In J. Ritchie and J. Lewis (Eds). Qualitative Research Practice: a guide for social science students and researchers. London: Sage.

Smith, E. (2005) Telephone interviewing in healthcare research: a summary of the evidence. Nurse Researcher. 12 (3): 32-41.

Snape, D. \& Spencer, L. (2003) The foundations of qualitative research. In J. Ritchie and J. Lewis (Eds). Qualitative Research Practice: a guide for social science students and researchers. London: Sage.

Van Teijlingen, E. \& Hundley, V. (2002) The importance of pilot studies. Nursing Standard. 16 (40): 33-36.

Virginia Tech Digital Library and Archives. (2011) ETD Statistics and information. Available at: http://scholar.lib.vt.edu/theses/data/ (accessed 2 August 2014). 
Table 1. Semi-structured I nterview Schedule

1. Thinking back, how did you first become aware of ETDs? And, what was your thinking about them then?

2. What challenges/difficulties have you experienced while searching, accessing, downloading and using ETDs? And, what factors have contributed to these?

3. Did involvement in the earlier survey lead to you using ETDs more / promoting ETDs more to students and colleagues?

4. What opportunities/benefits have you experienced while searching, accessing and accessing, downloading and using ETDs? And, what factors enabled these?

5. Compared to printed copies, have ETDs changed the way you use and read theses/dissertations? And, or, has led to the use of more ETDs from other related disciplines?

6. Tell me more about the way you use an ETD?

7. If your own thesis/dissertation is available online, please tell me about any impacts this has had for you personally and/or professionally? Any impacts for your institution and/or your subject discipline?

8. Thinking of the future, how could we help potential users of ETDs to access them and use them optimally?

Note. Prompts were used to elicit additional information as needed. 
Table 2: Summary details of participants $(n=14)$

\begin{tabular}{|l|l|l|l|}
\hline \multicolumn{1}{|c|}{ Faculty $(\mathrm{n}=6)$} & \multicolumn{1}{c|}{ Alumni $(\mathrm{n}=3)$} & \multicolumn{1}{c|}{ Students $(\mathrm{n}=5)$} \\
\hline U.K. & $\begin{array}{l}\text { 4- Three held PhDs } \\
\text { and one a Masters } \\
\text { degree }\end{array}$ & 0 & $\begin{array}{l}\text { 3- Two enrolled in PhD } \\
\text { programs and one enrolled } \\
\text { in a program offering a } \\
\text { professional doctorate }\end{array}$ \\
\hline U.S. & 2 - Both held PhDs & 3 - Recent PhD graduates & $\begin{array}{l}\text { 2- Enrolled in PhD } \\
\text { programs }\end{array}$ \\
\hline
\end{tabular}

U.K. = United Kingdom; U.S. = Unites States 
Table 3: Overview of Themes and Sub-themes

\begin{tabular}{|c|c|c|}
\hline Theme & Sub theme & Explanatory example/ comment \\
\hline \multirow{5}{*}{$\begin{array}{l}\text { Initial } \\
\text { exposure } \\
\text { and effect }\end{array}$} & $\begin{array}{l}\text { Awareness through knowledge } \\
\text { provision/ instruction }\end{array}$ & $\begin{array}{l}\text { Received information on ETDs through library/teaching } \\
\text { at start of doctorate, typically highlighting local IR }\end{array}$ \\
\hline & Awareness through discovery & Discovered ETDs in course of wider literature search \\
\hline & Awareness through supervisory role & Became aware through his/her students' work \\
\hline & Conceptual impact & ETDs showed what end product could look like - useful \\
\hline & Positive reaction & ETDs seen as potentially very useful \\
\hline \multirow{3}{*}{$\begin{array}{l}\text { Process of } \\
\text { engagement: } \\
\text { searching for } \\
\text { ETDs }\end{array}$} & Focal and local & Searching confined to focal topic area and local IR \\
\hline & Wide and general & $\begin{array}{l}\text { Searching generic databases (e.g. Google; CINAHL) in } \\
\text { which ETDs may sometimes be cited }\end{array}$ \\
\hline & Lack of knowledge & Unsure of where to find ETDs apart from local IR \\
\hline \multirow{3}{*}{$\begin{array}{l}\text { Process of } \\
\text { engagement: } \\
\text { accessing } \\
\text { ETDs }\end{array}$} & Unable to get full text & $\begin{array}{l}\text { IR or portal does not provide full text download of } \\
\text { desired ETD - can lead to disengagement }\end{array}$ \\
\hline & Benefits of full text & Fast and full access to useful resources \\
\hline & Discovering beyond discipline & $\begin{array}{l}\text { Discovering potentially relevant ETDs from other } \\
\text { disciplines in course of accessing others }\end{array}$ \\
\hline \multirow{4}{*}{$\begin{array}{l}\text { Process of } \\
\text { engagement: } \\
\text { handling } \\
\text { ETDs }\end{array}$} & Strategic, selective appraisal & $\begin{array}{l}\text { Use of abstract, table of contents, and focus on key } \\
\text { part (e.g. through key word search in PDF document) }\end{array}$ \\
\hline & Holistic appreciation & $\begin{array}{l}\text { ETD gives bird's eye view of the whole thesis - enables } \\
\text { flexible reading of different parts }\end{array}$ \\
\hline & Challenge of on-screen reading & Sustained on-screen reading difficult for many \\
\hline & Download or discard? & $\begin{array}{l}\text { Useful to have the choice, but storage capacity for e } \\
\text { documents can be difficult }\end{array}$ \\
\hline \multirow{4}{*}{$\begin{array}{l}\text { Process of } \\
\text { application: } \\
\text { using ETDs }\end{array}$} & $\begin{array}{l}\text { Using ETDs for own doctoral } \\
\text { literature review }\end{array}$ & $\begin{array}{l}\text { Focusing on relevance to own topic - particularly useful } \\
\text { for development of a study protocol for doctorate }\end{array}$ \\
\hline & $\begin{array}{l}\text { Using ETDs for in-depth } \\
\text { knowledge of methodology for } \\
\text { own thesis }\end{array}$ & $\begin{array}{l}\text { ETDs can provide very relevant and easily accessed } \\
\text { exemplars of methodological approaches - more so } \\
\text { than journals }\end{array}$ \\
\hline & $\begin{array}{l}\text { Using ETDs as structure and } \\
\text { format exemplars for own thesis }\end{array}$ & $\begin{array}{l}\text { ETDs can provide very useful exemplars for macro and } \\
\text { micro aspects of structuring and formatting a thesis }\end{array}$ \\
\hline & Teaching others using ETDs & $\begin{array}{l}\text { Guiding students to access, constructively critique and } \\
\text { use knowledge from ETDs - may be inter-disciplinary }\end{array}$ \\
\hline \multirow{7}{*}{$\begin{array}{l}\text { Evaluation: } \\
\text { conceptions, } \\
\text { culture and } \\
\text { change }\end{array}$} & ETDs improve accessibility & ETDs vastly more accessible than hard bound copies \\
\hline & $\begin{array}{l}\text { Need to raise awareness of ETDs } \\
\text { and proactively educate }\end{array}$ & $\begin{array}{l}\text { Students and supervisors need to know more about the } \\
\text { what, why, where, and how of ETDs }\end{array}$ \\
\hline & $\begin{array}{l}\text { Need for one or more key portals } \\
\text { for ETDs }\end{array}$ & $\begin{array}{l}\text { Organised collaboration needed to organise ETDs in a } \\
\text { similar way to Cochrane database }\end{array}$ \\
\hline & $\begin{array}{l}\text { ETDs can offer more than journal } \\
\text { papers }\end{array}$ & $\begin{array}{l}\text { As overall exemplars and as in-depth sources of } \\
\text { knowledge, especially on applied methodology }\end{array}$ \\
\hline & $\begin{array}{l}\text { ETDs can also have low visibility, } \\
\text { both for readers and their authors }\end{array}$ & $\begin{array}{l}\text { Hidden in cyberspace, do they lack the status of the } \\
\text { old bound copies? Do their authors know their impact? }\end{array}$ \\
\hline & Inter-country \& cultural comparisons & Countries differ in approach. Is English too dominant? \\
\hline & Potential to break boundaries & ehicle for inter-disciplinary learning \\
\hline
\end{tabular}

Note. Use of bold typeface denotes strong, recurrent sub-theme 